
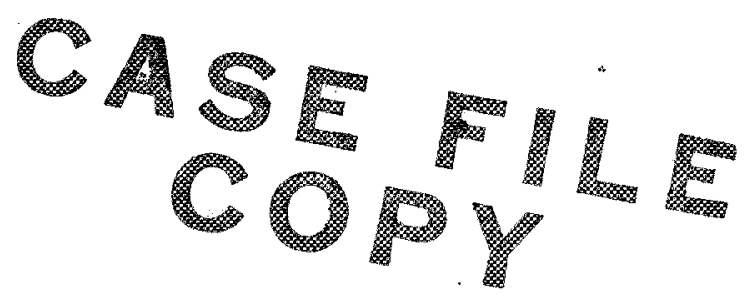

\title{
THERMAL FATIGUE TESTING OF SIMULATED TURBINE BLADES
}

by D. A. Spera, F. D. Calfo, and P. T. Bizon

Lewis Research Center

Cleveland, Ohio

TECHNICAL PAPER proposed for presentation at

National Air Transportation Meeting sponsored by the

Society of Automotive Engineers

Atlanta, Georgia, May 10-13, 1971 


\section{INTRODUCTION}

The objective of this investigation was to provide thermal-fatigue data on simulated turbine blades to be used for evaluating life prediction theories. The experimental work described in this paper is part of a general study of thermal fatigue conducted by the Lewis Research Center. The problem of thermal-fatigue cracking in turbine blades has been under investigation at Lewis for more than 14 years. Early work is given in Refs, 1 and 2. A general program of research is now being followed to make it possible to predict and eventually extend thermal-fatigue life. This program has been described in Ref. 3 and is shown schematically in Fig. 1.

Our goal is the ability to predict the thermal-fatigue performance of an engine component from its shape, material, environment, and loading As shown in Fig. 1, three series of tests are now providing data for deriving and evaluating this prediction theory: (a) Isothermal material tests such as tensile, creep-rupture, and low-cycle fatigue (Refs. 4 to 8), (b) thermal-fatigue tests on simple wedge specimens using the fluidized-bed technique (Ref, 9), and (c) burner-rig tests on simulated turbine blades, with and without internal cooling. This paper presents data on the uncooled blades from the burner-rig test series.

\section{ABSTRACT}

Simulated turbine blades were subjected to transient and steady-state heating and spanwise loading in a Mach 1 burner rig. Leading-edge cracks were produced which were similar to thermal-fatigue cracks observed during engine service. Crack initiation and propagation data were obtained for a variety of test conditions.

The simulated turbine blades consisted of coated and uncoated IN 100 and B 1900 cambered airfoils with grips for application of spanwise load to simulate centrifugal stress. Test variables were blade temperature, spanwise load, and steady-state (hold) time. The Mach 1 gas velocity substantially reduced conventional creep rupture life. This caused a substantial reduction in thermal fatigue life. Coating effectiveness was below that for low velocity tests. 
Material tests on simple specimens have led to empirical rules (Refs, 4 to 6) and a general theory (Refs. 7, 8, and 10) for predicting cyclic life at high temperature. This theory has been evaluated using fluidized-bed thermal-fatigue data on a variety of alloys (Ref. 9). But both the isothermal and fluidized-bed tests were conducted on very simple specimens under idealized laboratory conditions. Therefore, rig tests of simulated parts are necessary to provide a more complete verification of theory prior to its application to actual engine components.

\section{EXPERIMENTAL APPARATUS AND PROCEDURE}

Simulated Turbine Blade Specimens

The configuration of the simulated turbine blades tested in this investigation is shown in Fig. 2. The external shapes of all specimens were the same. The airfoil design was based on the 65 percent span section of the first stage blade in a P\&WA JT4 engine. Grips were provided on each end of the airfuil section to permit tensile loading to simulate centrifugal forces.

The simulated blades were precision cast from the nickel-base alloys IN 100 and B 1900. The external surfaces of most of the specimens were given an aluminide coating. The holes and slots in the film-cooled specimens were cut by electrical di scharge machining.

\section{Test Facility}

Figure 3(a) shows a general view of the facility used for thermal fatigue testing of the simulated turbine blades. It consisted of two main parts: (1) a Mach 1 burner fueled with natural gas, having a capacity of $0.5 \mathrm{~kg} / \mathrm{sec}(1 \mathrm{lb} / \mathrm{sec})$ at $1900 \mathrm{~K}\left(3000^{\circ} \mathrm{F}\right)$, and (2) a hydraulic loading fixture capable of applying $89000 \mathrm{~N}(20000 \mathrm{lb})$ of load through parallel platens. Burners of this type have been used at Lewis to study oxidation, erosion, and corrosion in superalloys (Ref, 11). The entire loading fixture pivoted so as to move the specimen in and out of the burner exhaust. In this way the burner could operate at steady-state while the specimen was thermally cycled. This greatly simplified burner operation and reduced thermal fatigue in the burner itself.

Figure $3(\mathrm{~b})$ shows details of the test section of the facility. The specimen was clamped securely to the heavy platens, eliminating the thermal bowing which is usually present in cambered airfoils. This stabilized the specimen and also greatly simplified the subsequent stress analysis. During operation, the grips and platens were covered and air-cooled. Because the objective of this investigation was to obtain data to check a theory, and not to simulate engine service, the end restraint did not limit the applicability of the data to the theory.

Air for internal cooling of the specimens entered and exited through the platens. External air-cooling of the test section could be accomplished using the nozzle to the rear of the specimen. However, in the tests described herein, cooling was only by radiation and conduction through the grips. 
Danforth (Ref, 12) has described a similar thermal-fatigue rig in which uncambered (symmetrical) airfoil specimens were testec under load in a closed hot-gas tunnel. This tunnel operated at elevated pressure and the burner was cycled between idle and maximum temperatures. A similar rig is in operation at Lewis.

Controls and Instrumentation

The primary test parameter was the leading edge temperature at steady state. This was monitored periodically with an optical pyrometer of the disappearing-wire type. Burner gas temperature was adjusted and automatically controlled according to outputs from thermocouple probes in the plenum of the burner.

During heating, transient temperatures and strains at the leading edges of calibration specimens were measured by the instruments shown in Fig. 3(c). Temperatures at midspan were recorded with an electro-optical pyrometer which responded to infrared radiation from a small area of the leading edge. Its output was calibrated against the disappearing-wire pyrometer. Steady-state temperatures were also obtained from infrared photographs of the pressure surface.

The electro-optical extensometer was used to measure total strain (mechanical plus free thermal expansion) over a $1.3 \mathrm{~cm}(0.5 \mathrm{in}$.) gage length along the leading edge. The gage length was defined by two small platinum wires fastened at right angles to the leading edge. A high-intensity light behind the wires produced a silhouette which was focused on a photomultiplier tube. The output of this tube changed with changes in the distance between the wires. The system also included a remote positioning table and image-splitting optics for increased accuracy. The extensometer had a resolution of approximately 0.5 micrometers ( $20 \mu \mathrm{in}$.).

The specimens were moved out of the fields of view of the pyrometer and exten someter for cooling. This made it necessary to calculate transient temperatures and strains for that part of the cycle. Calculations were made using the assumption that heat loss was primarily by radiation.

\section{RESULTS AND DISCUSSION}

\section{Strain and Temperature Cycles}

Typical strains and temperatures at the leading edge of a simulated turbine blade are shown in Fig。4. Strain is plotted versus temperature, with elapsed time indicated along the curve. Strains were always compressive, indicating that the leading edge temperature was always above the average temperature in the airfoil. This is a result of the relatively slow radiation and conduction cooling. The heating portion of Fig. 4 was obtained from measurements on a calibration specimen. The cooling portion was calculated. 
Large temperature gradients were ubserved in the airfoil sections under steadystate as well as transient conditions. This is indicated in Fig. 4 by the substantial compressive strain after 180 seconds of heating. Figure 5 shows these temperature gradients more directly. Infrared photography of the pressure surface at steady state revealed a temperature range of over $200 \mathrm{~K}\left(360^{\circ} \mathrm{F}\right)$ for a leading edge temperature of $1340 \mathrm{~K}\left(1950^{\circ} \mathrm{F}\right)$.

This temperature distribution produced higher strains in the test specimens than it would in a turbine blade. This was because the restrained airfoil specimen could not warp like an unrestrained blade to relieve thermal stress. This was somewhat of an advantage because it accelerated the testing without raising the leading edge temperature. Another accelerating factor was the size of the temperature gradients themselves. They were larger in the specimen than in an actual turbine blade due to heat losses by radiation to a cold room zather than to hot neichoring blades and vanes.

\section{Cycles to First Crask}

The cycle number at which the first crack starts to propagate is defined as the thermal fatigue life. This number of cycles was determined by plotting crack area (or length) versus cycle number. Figure 6 shows some typical thermal fatigue cracks in IN 100 turbine blade specimens. Cracks in B 1900 specimens were very similar. All cracks started at the leading edge, usually quite near midspan. The start of cracking in the specimens was determined by periodic visual inspections of the leading edge at a magnification of $40 \mathrm{X}$. These inspections were made without removing the specimen from the loading fixture. Once cracks were observed, the specimen was removed at intervals from the test rig, and the location and length of the major cracks were measured.

Table I summarizes the thermal fatigue data obtained in this investigation on uncooled (solid) blade specimens. The IN 100 tests were conducted to study three effects: (1) maximum temperature, (2) coating, and (3) lag time, which is the time interval between the start of heating and the application of the spanwise load. The B 1900 specimens were all coated and were used to study the effect of hold time at maximum temperature and load。

Figure 7 shows the effects of maximum temperature and coating on the thermal fatigue resistance of the IN 100 specimens. Cycles to first crack was found to be extremely sensitive to maximum temperature. In uncoated specimens, life was reduced by a factor of 10 for each $75 \mathrm{~K}\left(135^{\circ} \mathrm{F}\right)$ increase in temperature. The aluminide coating increased thermal fatigue resistance but only half as much as in earlier fluidizedbed tests on IN 100 (Ref. 10). The difference may be related to the low gas velocity in the fluidized beds compared with the Mach 1 velocity in the burner rig. The effects of high gas velocity on life are discussed in more detail in the section LIFE PREDICTION. 
The effect of load and lag time was determined for the cuated IN 100 specimens at $1225 \mathrm{~K}\left(1750^{\circ} \mathrm{F}\right)$. Referring to Table I, life was 1050 cycles without load (average of specimens 10 and 19) and 1650 cycles with continuous load (specimen 12). This increase may be related to the fact that tensile load offset the compressive thermal stress at the leading edge. But when load was applied 30 seconds after the start of each heating cycle, life was substantially reduced, to 500 cycles (average of specimens 8 and 17). This reduction can be explained by referring to Fig. 4. The maximum compressive thermal strain occurred after only 5 seconds of heating. Applying the tensile load after 30 seconds therefore did not reduce the maximum compressive strain. However, it did increase the tensile strain during cooling, causing an increase in strain range and a subsequent decrease in life. Therefore, in simulating a turbine blade cycle, the correct sequence of thermal and mechanical loading should be maintained.

Figure 8 shows the effect of hold time at a maximum temperature of $1340 \mathrm{~K}$ $\left(1950^{\circ} \mathrm{F}\right)$ on the lives of coated B 1900 specimens. Life is given both in cycles and hours to first crack. A hold time of unly 0.1 hour caused a sharp reduction in cyclic life. This reduction was observed for tests with and without spanwise load, Increasing the hold time from 0.1 to 1 hour caused little change in the cycles to failure but a large increase in the total time to failure. For hold times longer than 1 hour, the total time to failure approached a constant value of about 90 hours.

\section{Crack Propagation}

Crack growth rates are given in Table I on an area basis to make them somewhat independent of the airfoil geometry. Crack area was calculated from surface measurements, assuming the crack front to be a straight line, Figure 9 shows some typical crack propagation data for IN 100 airfoils at $1225 \mathrm{~K}\left(1750^{\circ} \mathrm{F}\right)$. Crack area was found to be quite linear with cycle number, defining a clear starting point for crack propagation. This starting point was taken as the cycles to cause cracking. Tests on coated and uncoated specimens, such as shown on curves A and B in Fig. 9, produced approximately the same growth rates. This indicates that the coating can delay crack initiation, but it probably cannot slow crack growth. Curves C and D show the effect of lag time on the crack initiation period. In general, crack area growth rates were found to be inversely proportional to the thermal fatigue lives of the uncoated specimens. This relationship was discussed earlier in Ref. 10.

\section{Oxidation and Erosion}

The Mach 1.0 gas velocity used in these tests accelerated the processes of oxidation and erosion (Ref. 11). Figure 6 shows typical examples of oxidation and erosion at the leading edge of the specimens. Without a coating (Fig. 6(a)), material is lost through cycles of oxidation, scaling, and flaking. The coating (Fig. 6(b)) preserved the original airfoil contour as well as extending life. 
Figure 6(c) shows the final condition of the lowest temperature but longest life specimen. Considerable material was lost from the leading edge of this uncoated specimen. Heavy oxide scales obscured the tips of the thermal fatigue cracks For a maximum temperature of $1170 \mathrm{~K}\left(1650^{\circ} \mathrm{F}\right)$, Fig. 7 indicated that coating this specimen would not have increased its cyclic life. Huwever, a coating would still be necessary to preserve the leading edge contour.

\section{LIFE PREDICTION}

This investigation was conducted primarily to provide data to evaluate a theory for predicting thermal fatigue life. This theory has previously been described in detail (Refs, 7, 8, and 10). Two separate failure modes are considered: conventional low-cycle fatigue and cyclic creep-rupture. Low-cycle fatigue life is calculated from the imposed strain cycle and the short-time tensile properties of the material. Manson's Method of Universal Slopes is used to make this calculation. Cyclic creep-rupture life is calculated from the stress and temperature cycles and the conventional monotonic creep-rupture data. A linear interaction between the two failure modes is assumed.

This theory has been used successfully to correlate the results of fluidized-bed tests of the same alloys tested herein (Ref. 9). However, in this investigation the theory predicted lives that were approximately 10 times too long. For example, in Fig. 8, the asymptotic value for total hours to failure with long hold times was predicted to be about 2500. By test it was only 90 hours. It was hypothesized that the error lay in the monotonic creep-rupture data used in the calculations and not in the theory itself. According to this hypothesis, the Mach 1 gas velocity greatly reduces creep-rupture time compared to the furnace test data used in the life calculations. This was subsequently verified by data from the literature (Refs, 13 and 14) and by tests on IN 100 and coated B 1900 specimens.

The results of the latter tests are presented in Table II and Fig. 10. Test specimens were conventional creep bars, $0.63 \mathrm{~cm}\left(0.25 \mathrm{in}_{\mathrm{v}}\right)$ in diameter. These bars were stressed in the same loading fixture shown in Fig, 3. Compared to furnace tests, 80 to 95 percent of the rupture time is lost when the gas velocity is raised to Mach 1,0 , depending on the temperature,

If furnace rupture data were adjusted for gas velocity according to Fig, 10, considerably shorter lives would be predicted. Again referring to Fig. 8, the predicted asymptote would then be about 100 hours, rather than 2500. This is quite close to the test value indicating that modification of the input creep data rather than the theory is required. The actual technique for calculating the effects of high-velocity gas heating on conventional creep-rupture life has not yet been determined. Effects on creep rate, ductility, and rupture time must be investigated. In addition to velocity, such parameters as gas pressure, gas temperature, angle of attack, surface-to-volume ratio, and stress level may be important. 


\section{SUMMARY AND CONCLUSIONS}

Thermal-fatigue tests were conducted on simulated turbine blades in a highvelocity natural gas burner rig. These tests provided data which will be used to evaluate a life prediction theory under conditions which closely simulate engine service. The effects of maximum temperature, gas velocity, coating, spanwise loading, and steady-state hold time were investigated. The following conclusions were drawn from a preliminary examination of the test data:

1. A theory for predicting the thermal-fatigue resistance of turbine blades must include the effect of high-velocity gas environment. It appears that this effect can be included by substituting creep data obtained in an appropriate high velocity gas environment for conventional creep data in the theory.

2. High-velocity gas heating may reduce thermal-fatigue resistance substantially below that for static heating. This reduction may be related to the adverse effect of high-velocity gas heating on creep-rupture life. Preliminary creep-rupture tests showed that a gas velocity of Mach 1 can shorten life by 80 to $\% 5$ percent.

3. An aluminide surface coating delayed thermal-fatigue cracking in the IN 100 turbine blade specimens. However, this delay was not as great as in earlier fluidizedbed (static heating) tests.

4. Cracks grow at a rate inversely proportional to the number of cycles required to start the crack in the uncoated alloy condition. Crack propagation rates were apparently not affected by the aluminide coating.

5. At lower temperatures and longer lives, surface coatings may not delay cracking, but they are still needed to reduce erosion and oxidation.

\section{REFERENCES}

1. D. F. Springsteen, C. A. Gyorgak, and J. R. Johnston, "Origin and Development of Leading-Edge Cracks in Turbojet Engine Buckets," NACA RM E57C12, 1957.

2. J. R. Johnston, J. W. Weeton, and R. A. Signorelli, "Engine Operating Conditions that Cause Thermal-Fatigue Cracks in Turbojet- Engine Buckets." NASA Memo $4-7-59 \mathrm{E}, 1959$.

3. D. A. Spera, "Thermal Fatigue of High-Temperature Materials." NASA SP-227, 1970 , pp. $43-57$.

4. S. S. Manson, and D. A. Spera, "Discussion of 'Low-Cycle Fatigue Damage of Udimet 700 at $1400 \mathrm{~F},{ }^{\prime}$ by C. H. Wells and C. P. Sullivan." Trans. ASM, vol. 58, no. 4, December 1965, pp. 749-752. 
5. S. S. Manson, "Interfaces Between Fatigue, Creep, and Fracture。" Int. J. Fracture Mech, , vol 2, no, 1, March 1966, pp. 327-363.

6. S. S. Manson, and G. R. Halford, "A Method of Estimating High-Temperature Low-Cycle Fatigue Behavior of Materials." Thermal and High-Strain Fatigue. London: The Metals and Metallurgy Trust, 1967, pp, 154-170.

7. D. A. Spera, "A Linear Creep Damage Theory for Thermal Fatigue of Materials," $\mathrm{Ph} . \mathrm{D}$. Thesis, $\mathrm{U}_{a}$ of Wisconsin, 1968.

8. D. A. Spera, "The Calculation of Elevated-Temperature Cyclic Life Considering Low-Cycle Fatigue and Creep" "NASA "TN D-5317, 1969.

9. D. A. Spera, M, A, H, Howes, and $\mathrm{P}_{\star} \mathrm{T}_{*}$ Bizon, "Thermal-Fatigue Resistance of 15 High-Temperature Alloys Determined by the Fluidized-Bed Technique." NASA TM X-52975, 1971.

10. D. A. Spera, "Calculation of Thermal-Fatigue Life Based on Accumulated Creep Damage." NASA TN D-5489, 1969.

11. J. R. Johnston and $R, L_{\text {。 }}$ Ashbrook, "Oxidation and Thermal Fatigue Cracking of Nickel- and Cobalt-Base Alloys in a High Velocity Gas Stream." NASA TN D-5376, 1969.

12. C. E. Danforth, "Designing to Avoid Fatigue in Long Life Engines。" Trans. SAE, vol. 75, Sect. 2, 1967, pp. 248-262.

13. V. G. Sorokin, I. N. Bogachev, Yu. G. Veksler, V. P. Lesnikov, and M. A. Filippov, "Short-Term Creep of Nickel in a High-Speed Air Flow." Metallovendenie i Termicheskaia Obrabotka Metallov, no. 3, 1970, pp. 2-5.

14. I. N. Bogachev, Yu. G. Veksler, and V. G. Sorokin, "Short-Term Creep of Metals and Alloys Under Conditions of Aerodynamic Heating." Izvest. V. U. Z, , Chernaya Met, no, 4, 1970, pp. 142-147.

15. Anon., "High Temperature, High Strength, Nickel Base Alloys," The International Nickel Company, Inc., 1964.

16. Anon., "A Technical Report on a New Cast Nickel Base Superalloy PWA 663

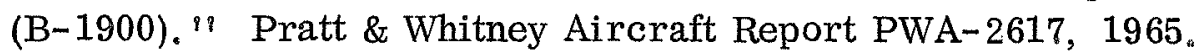


TABLE I. - THERMA L-FATIGUE DATA ON SIMULATED TURBINE BLADES

\begin{tabular}{|c|c|c|c|c|c|c|c|}
\hline $\begin{array}{l}\text { Specimen } \\
\text { number }\end{array}$ & $\begin{array}{c}\text { Maximum } \\
\text { temper } \\
\text { ature, } \\
\mathrm{T}_{\text {max }} \\
\mathrm{K}\end{array}$ & $\begin{array}{c}\text { Heating } \\
\text { time, } \\
\text { min }\end{array}$ & $\begin{array}{c}\text { Time } \\
\text { at } \\
\mathrm{T}_{\max ^{3}} \\
\text { min }\end{array}$ & $\begin{array}{c}\text { Average } \\
\text { spanwise } \\
\text { stress, } \\
\mathrm{N} / \mathrm{cm}^{2}\end{array}$ & $\begin{array}{l}\text { Lag time, } \\
\text { sec }\end{array}$ & $\begin{array}{l}\text { Cycles } \\
\text { to first } \\
\text { crack }\end{array}$ & $\begin{array}{l}\text { Crack area } \\
\text { growth rate, } \\
\mathrm{cm}^{2} / \text { cycle }\end{array}$ \\
\hline \multicolumn{8}{|c|}{ (a) IN 100} \\
\hline $\begin{array}{r}21 \\
1 \\
2 \\
3 \\
4\end{array}$ & $\begin{array}{l}1170 \\
1225 \\
1280 \\
1340 \\
1395\end{array}$ & 3 & 2 & $\begin{array}{c}0 \\
\vdots \\
\vdots \\
\vdots \\
\gamma\end{array}$ & $\overline{1}$ & $\begin{array}{r}3000 \\
530 \\
120 \\
18 \\
<10\end{array}$ & $\begin{array}{l}0.00010 \\
.00024 \\
.0017 \\
.010 \\
>.03\end{array}$ \\
\hline \multicolumn{8}{|c|}{ (b) IN 100, coated } \\
\hline $\begin{array}{r}10 \\
19 \\
9 \\
16 \\
6 \\
12 \\
8 \\
17\end{array}$ & $\begin{array}{l}1225 \\
1225 \\
1280 \\
1340 \\
1395 \\
1225 \\
1225 \\
1225\end{array}$ & 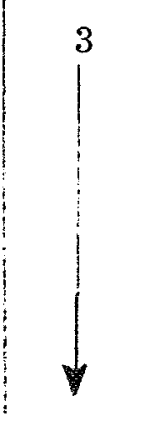 & 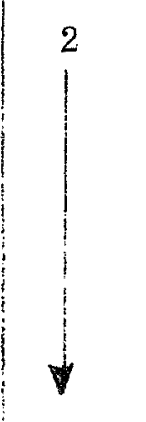 & $\begin{array}{c}\downarrow \\
13800 \\
13800 \\
13800\end{array}$ & $\begin{array}{r}-- \\
\vdots \\
\vdots \\
\gamma \\
0 \\
30 \\
30\end{array}$ & $\begin{array}{r}1030 \\
1070 \\
170 \\
82 \\
25 \\
1650 \\
440 \\
560\end{array}$ & $\begin{array}{c}0.00024 \\
.00015 \\
.0020 \\
.015 \\
.00014 \\
.00052 \\
.00050\end{array}$ \\
\hline \multicolumn{8}{|c|}{ (c) B 1900, coated } \\
\hline $\begin{array}{l}41 \\
40 \\
42 \\
43 \\
46 \\
44 \\
45\end{array}$ & 1340 & $\begin{array}{c}3 \\
3 \\
2 \\
2 \\
29 \\
59 \\
119\end{array}$ & $\begin{array}{r}2 \\
1.5 \\
.5 \\
.5 \\
27.5 \\
57.5 \\
117.5\end{array}$ & $\begin{array}{c}0 \\
0 \\
0 \\
13800 \\
\left.\right|^{\mid}\end{array}$ & $\begin{array}{l}-- \\
-- \\
-- \\
60\end{array}$ & $\begin{array}{r}120 \\
180 \\
225 \\
186 \\
81 \\
78 \\
46\end{array}$ & $\begin{array}{l}0.0012 \\
.00090 \\
.00074 \\
.0017 \\
.0039 \\
.0050 \\
.0059\end{array}$ \\
\hline
\end{tabular}


TABLE II. - COMPARISON OF CREEP-RUPTURE LIVES OBTAINED IN FURNACE AND MACH 1 BURNER, FOR IN 100 AND COATED B 1900

\begin{tabular}{|c|c|c|c|c|c|}
\hline \multirow[t]{2}{*}{ All oy } & \multirow{2}{*}{$\begin{array}{c}\text { Temper- } \\
\text { ature, } \mathrm{T} \text {, } \\
\mathrm{K}\end{array}$} & \multirow{2}{*}{$\begin{array}{c}\text { Stress, } \\
\mathrm{S}, \\
\mathrm{kN} / \mathrm{cm}^{2}\end{array}$} & \multicolumn{2}{|c|}{ Time to rupture, $t_{r}, h r$} & \multirow{2}{*}{$\begin{array}{c}\text { Life ratio, } \\
\text { Mach } 1 \text { burner } \\
\text { Furnace }\end{array}$} \\
\hline & & & Furnace $^{\mathrm{a}}$ & Mach 1 burnerb & \\
\hline IN 100 & $\begin{array}{l}1200 \\
1255 \\
1310\end{array}$ & $\begin{array}{r}20.7 \\
17.2 \\
7.6\end{array}$ & $\begin{array}{r}350 \\
83 \\
355\end{array}$ & $\begin{array}{r}75.7 \\
9.8 \\
27.2\end{array}$ & $\begin{array}{l}0.22 \\
.12 \\
.077\end{array}$ \\
\hline B 1900 , coated & $\begin{array}{l}1200 \\
1255 \\
1255 \\
1310\end{array}$ & $\begin{array}{r}20.7 \\
17.2 \\
14.5 \\
7.6\end{array}$ & $\begin{array}{r}340 \\
99 \\
240 \\
550\end{array}$ & $\begin{array}{l}57.3 \\
11.1 \\
23.4 \\
29.8\end{array}$ & $\begin{array}{l}0.17 \\
.11 \\
.098 \\
.054\end{array}$ \\
\hline
\end{tabular}

${ }^{a}$ Curve fit for literature furnace data. IN 100 data from Ref. 15. B 1900 data from Ref. 16.

IN 100: $\log \left(\mathrm{t}_{\mathrm{r}}\right)=30.90-4.03 \log (\mathrm{S})-0.0174 \mathrm{~S}-0.000316 \mathrm{~S}^{2}-0.01879 \mathrm{~T}$

B 1900: $\log \left(\mathrm{t}_{\mathrm{r}}\right)=-14.20-3.10 \log (\mathrm{S})-0.0544 \mathrm{~S}-0.0000193 \mathrm{~S}^{2}+26300 / \mathrm{T}$

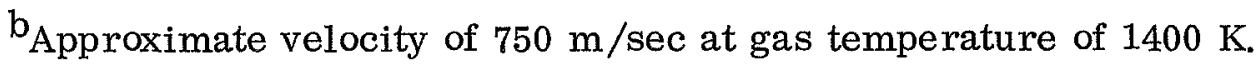




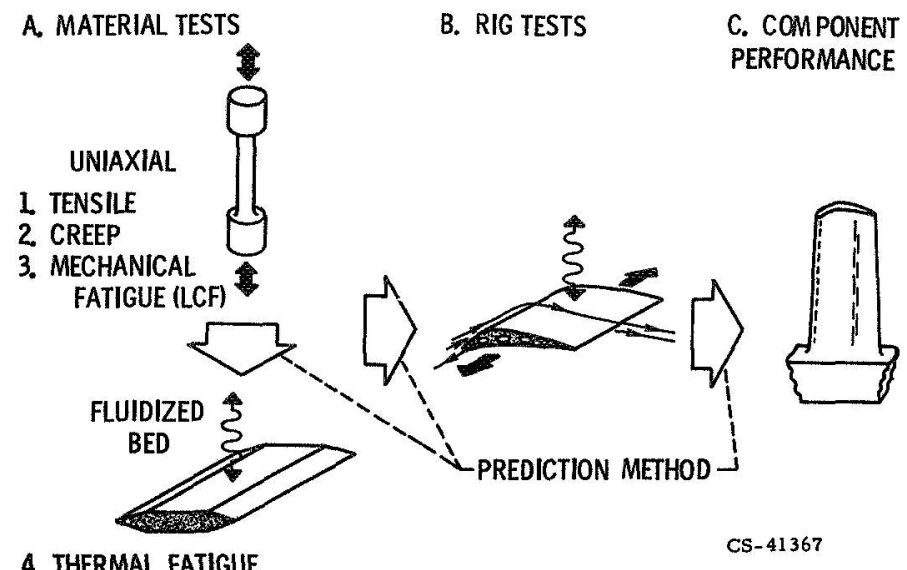

Figure 1 - General thermal-fatigue program.
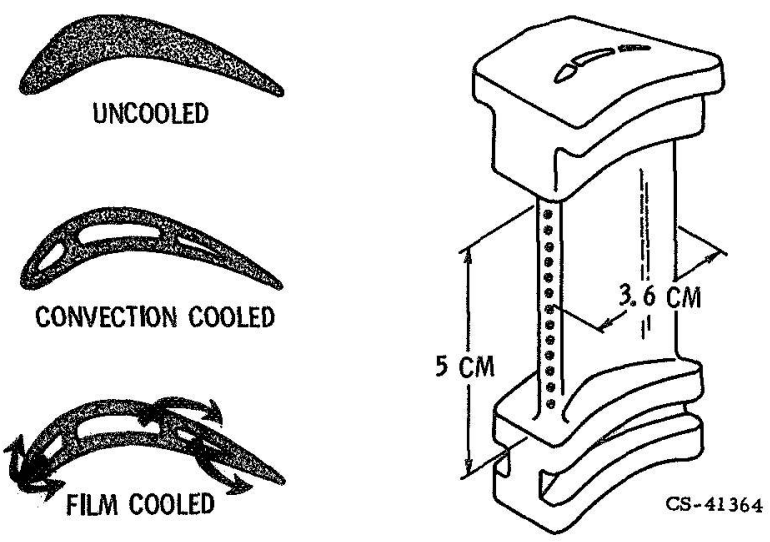

Figure 2. - Simulated turbine blades. 


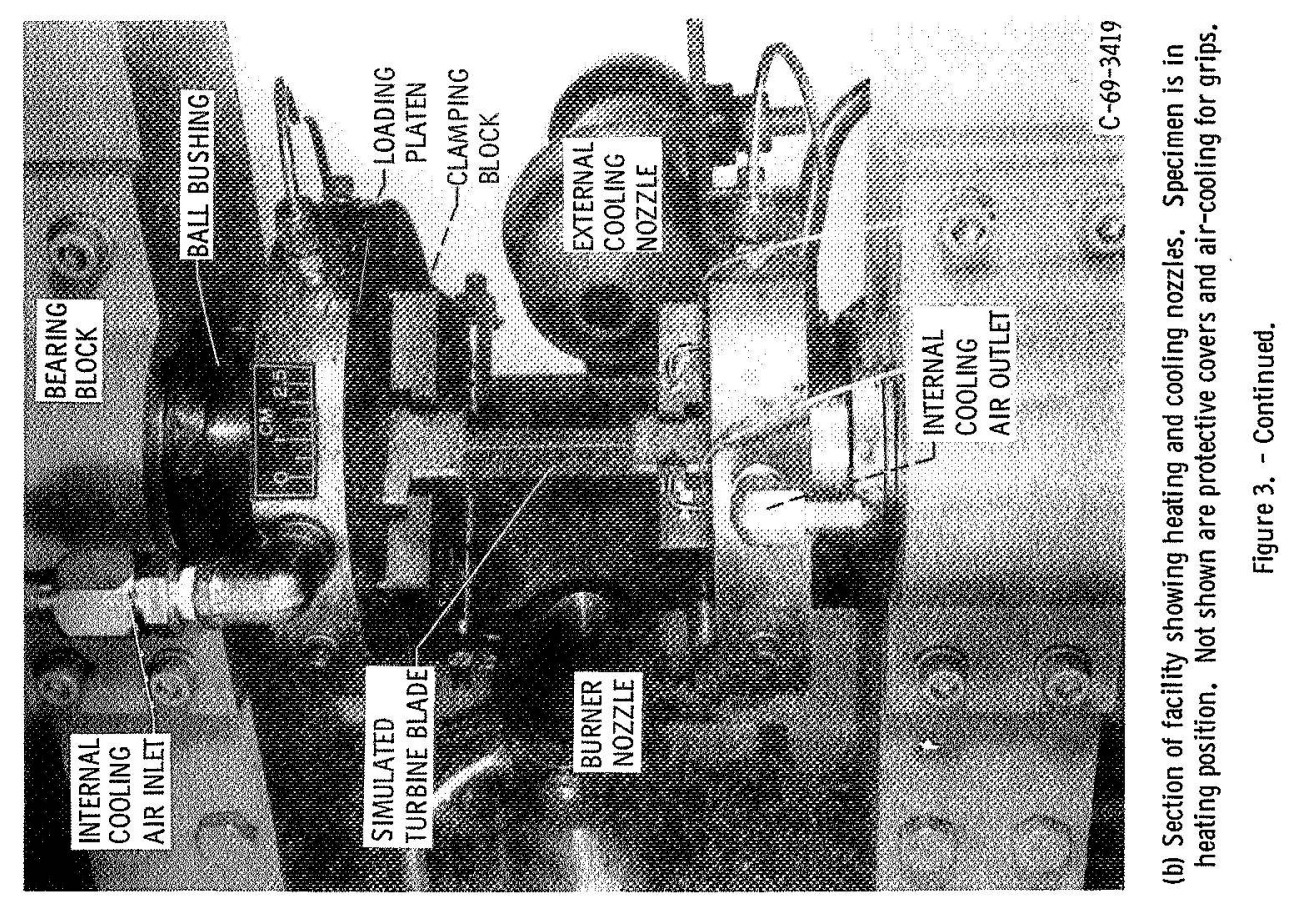

玨
N
o
O
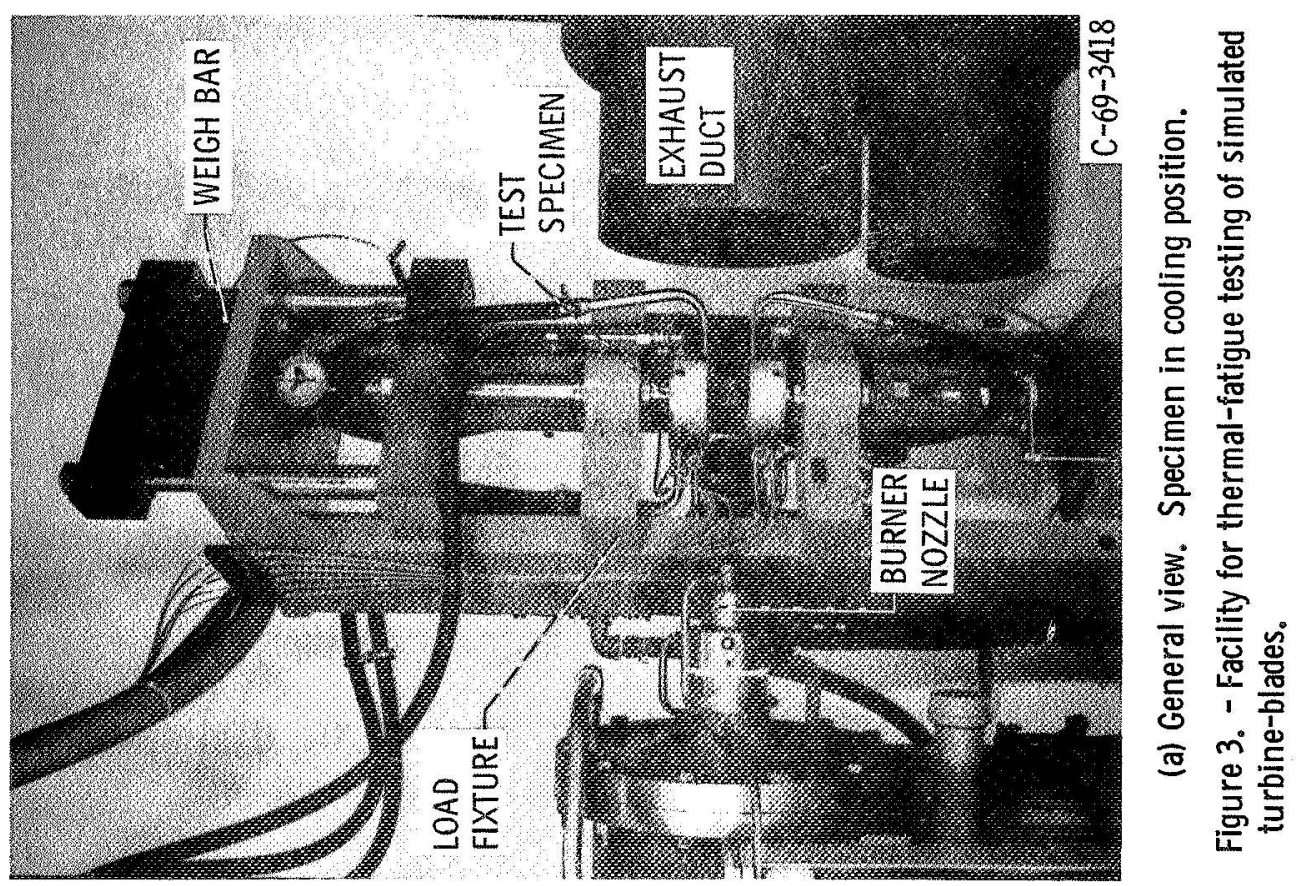


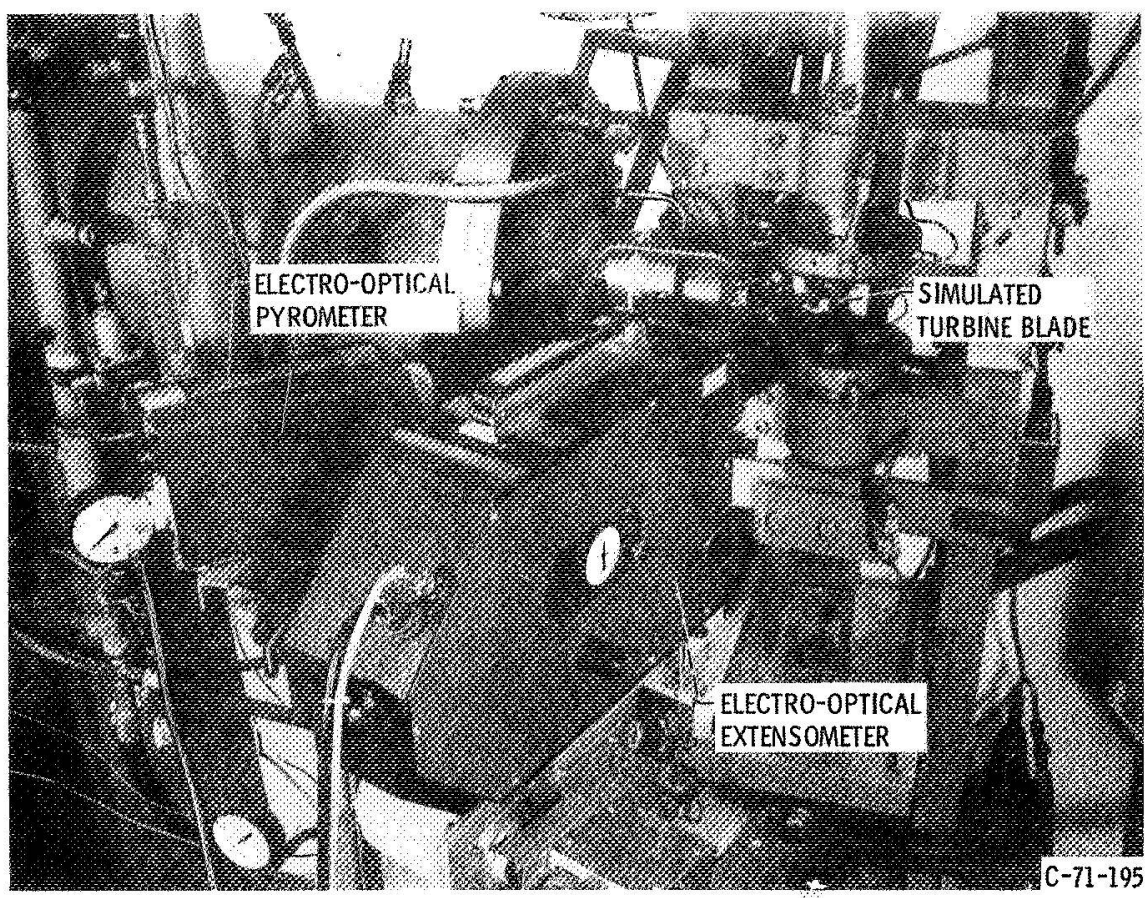

(c) Instrumentation for measuring strains and temperatures.

Figure 3. - Concluded.

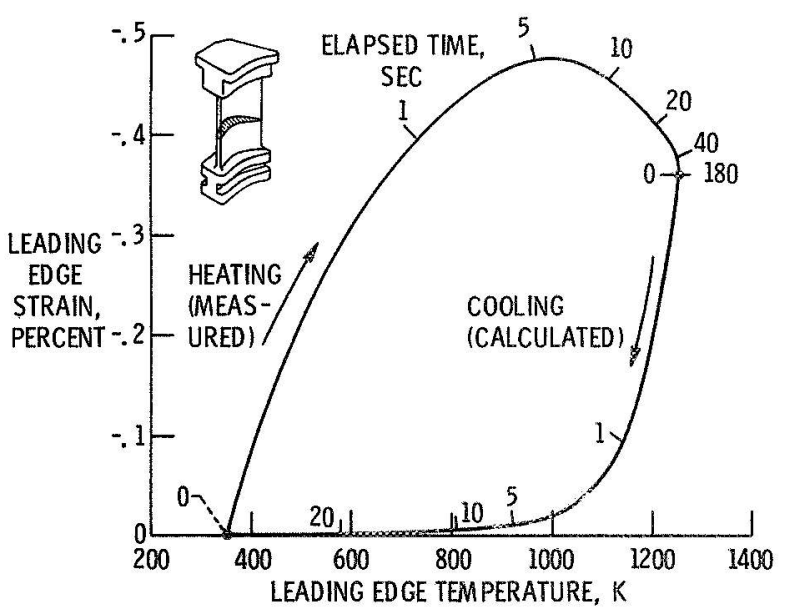

Figure 4. - Typical strain-temperature cycle at the leading edge of a simulated turbine blade (three-minute heating, one-minute coolingl.

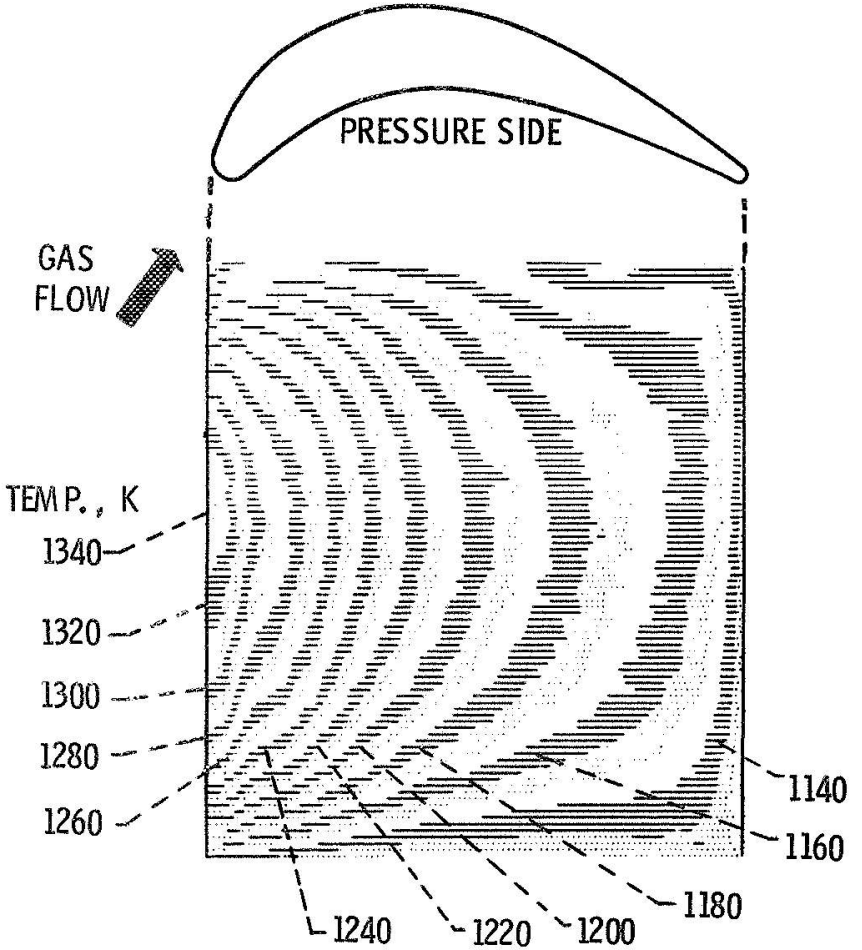

Figure 5. - Typical steady-state temperature distribution on pressure side of a simulated turbine blade, as determined by inf rared photography. 

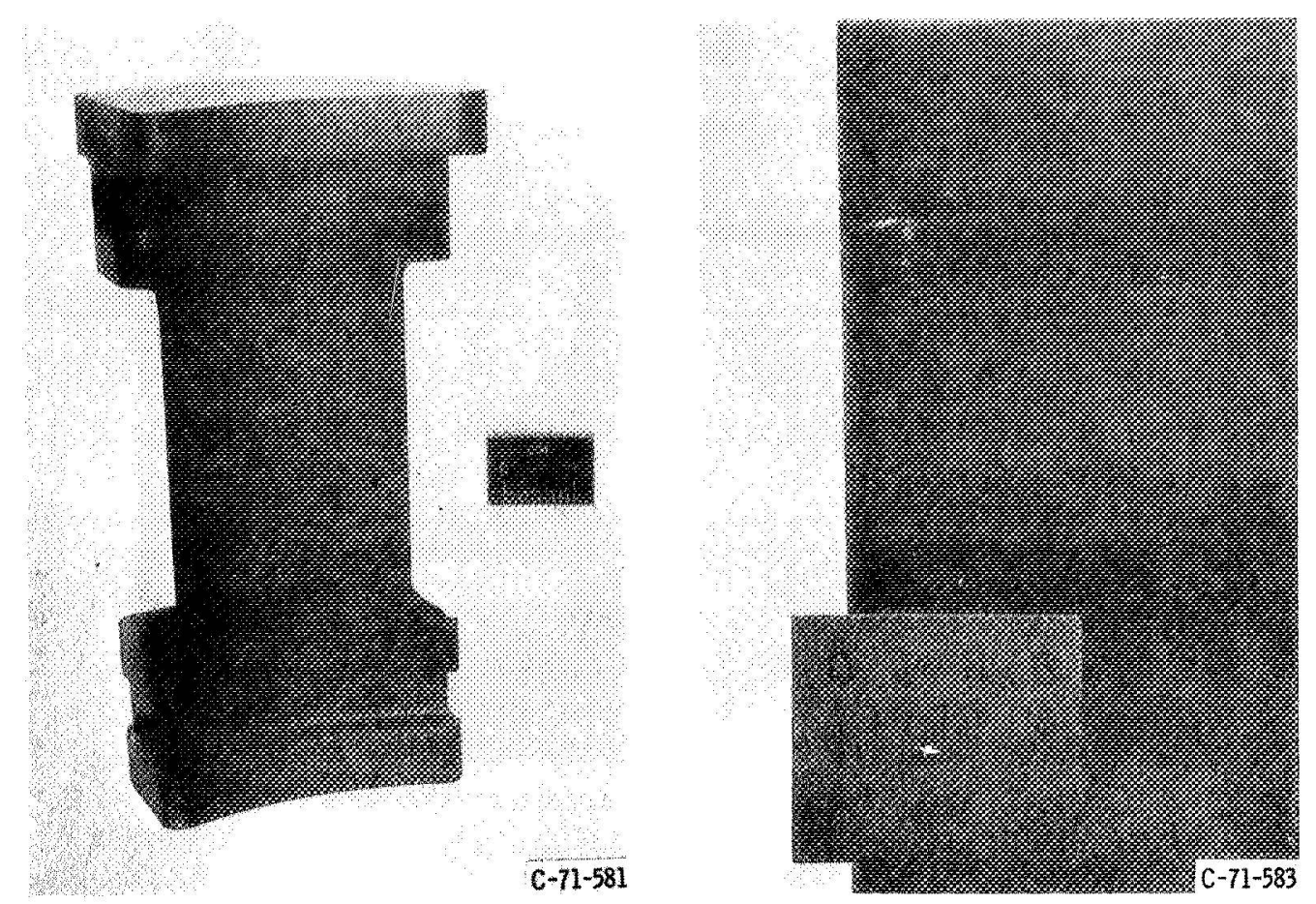

ț
$\vdots$
ò
No

(a) Uncoated, after $6003 \mathrm{~min}$. cycles $350 \mathrm{~K}=1280 \mathrm{~K}$ (spec. 2).
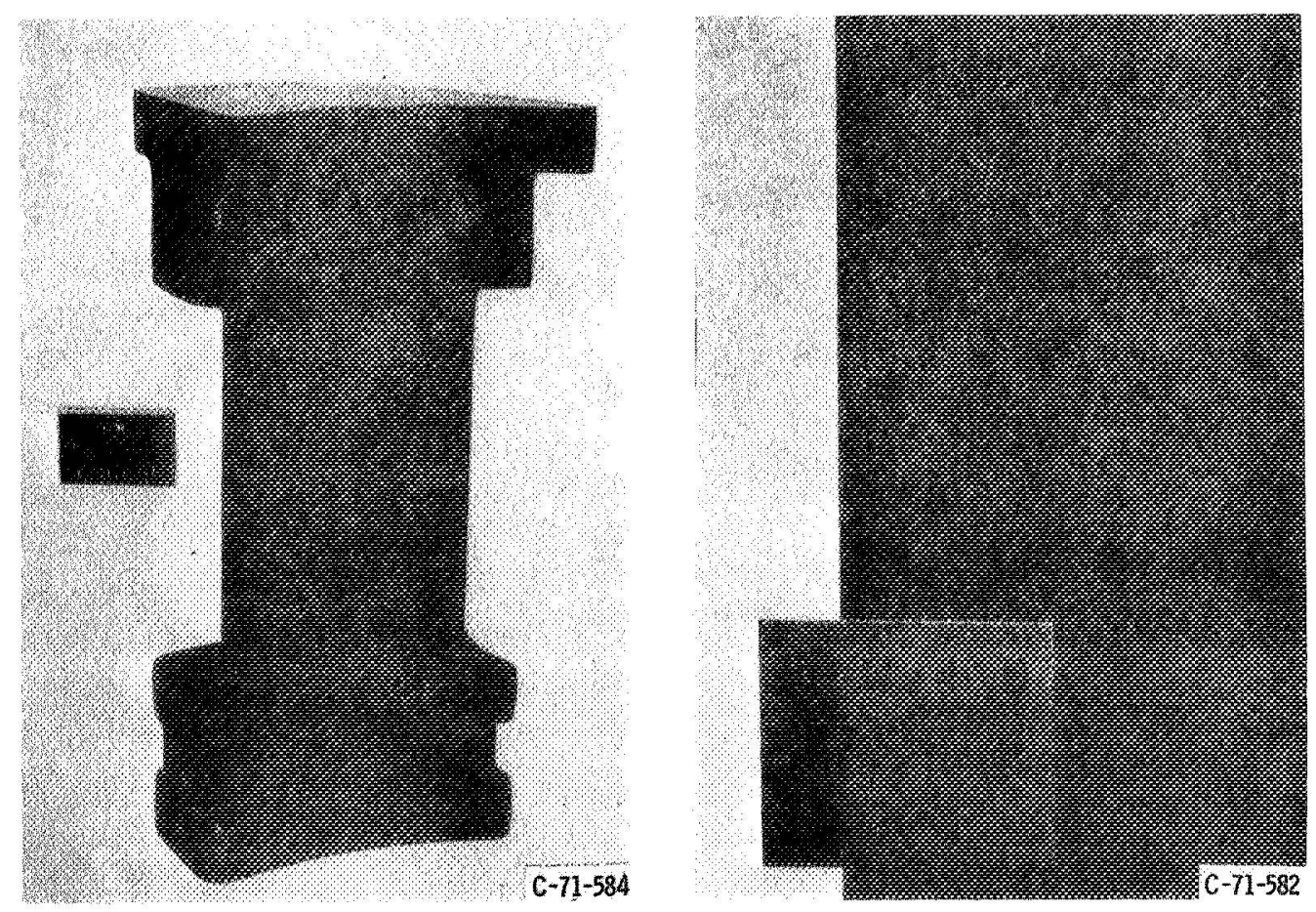

(b) Cozzed, after $8503 \mathrm{~min}$. cycles $350 \mathrm{~K}=1280 \mathrm{~K}$ (spec 9).

Figure 6. - Typical thermal-fatigue cracks in IN 100 simulated turbine blades. 

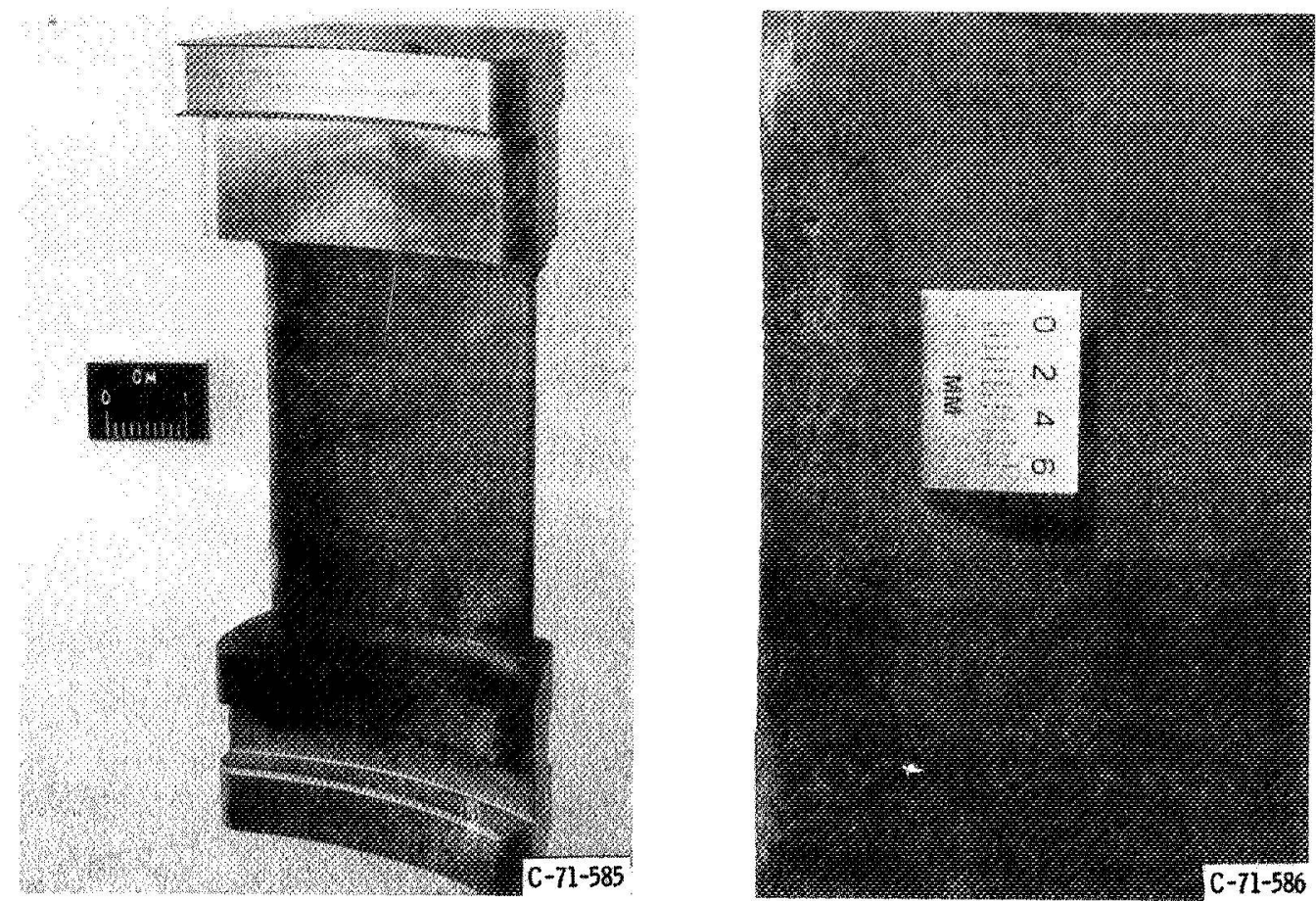

(c) Uncoated, after 4090 cycles $350 \mathrm{~K} \rightleftharpoons 1170 \mathrm{~K}$ (spec. 21 ).

Figure 6. - Concluded.

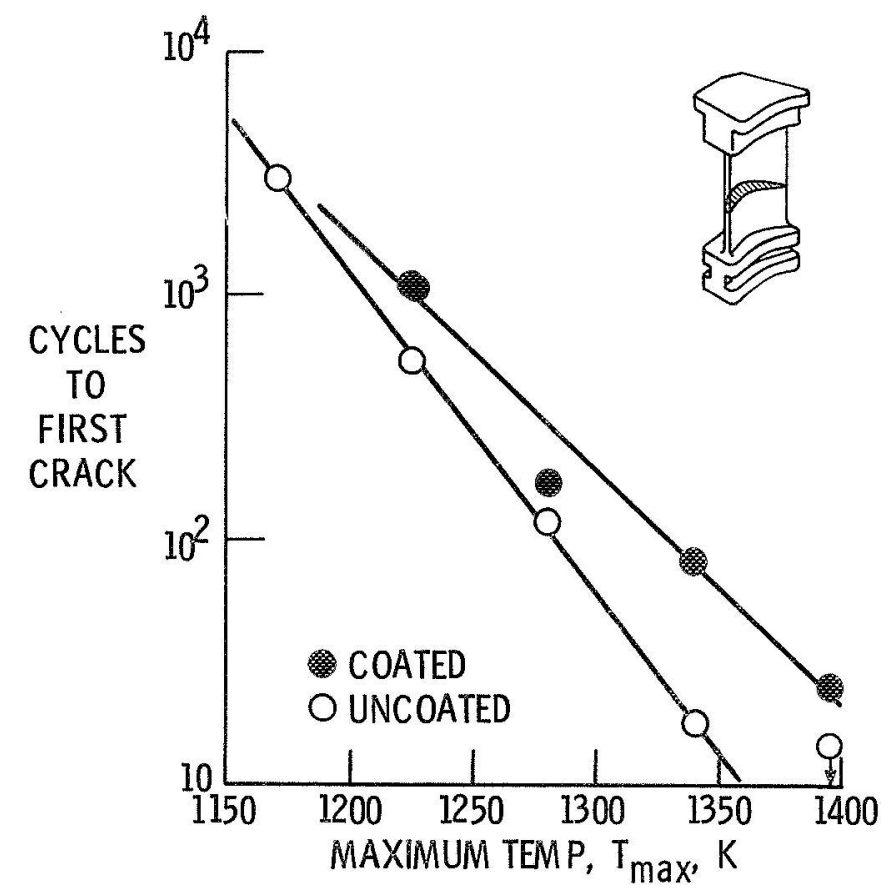

Figure 7. - Effect of maximum cycle temperature and coating on thermal fatigue life of IN 100 simulated turbine blades $\left(350 \mathrm{~K} \approx \mathrm{T}_{\text {max }}\right)_{\text {. }}$ 


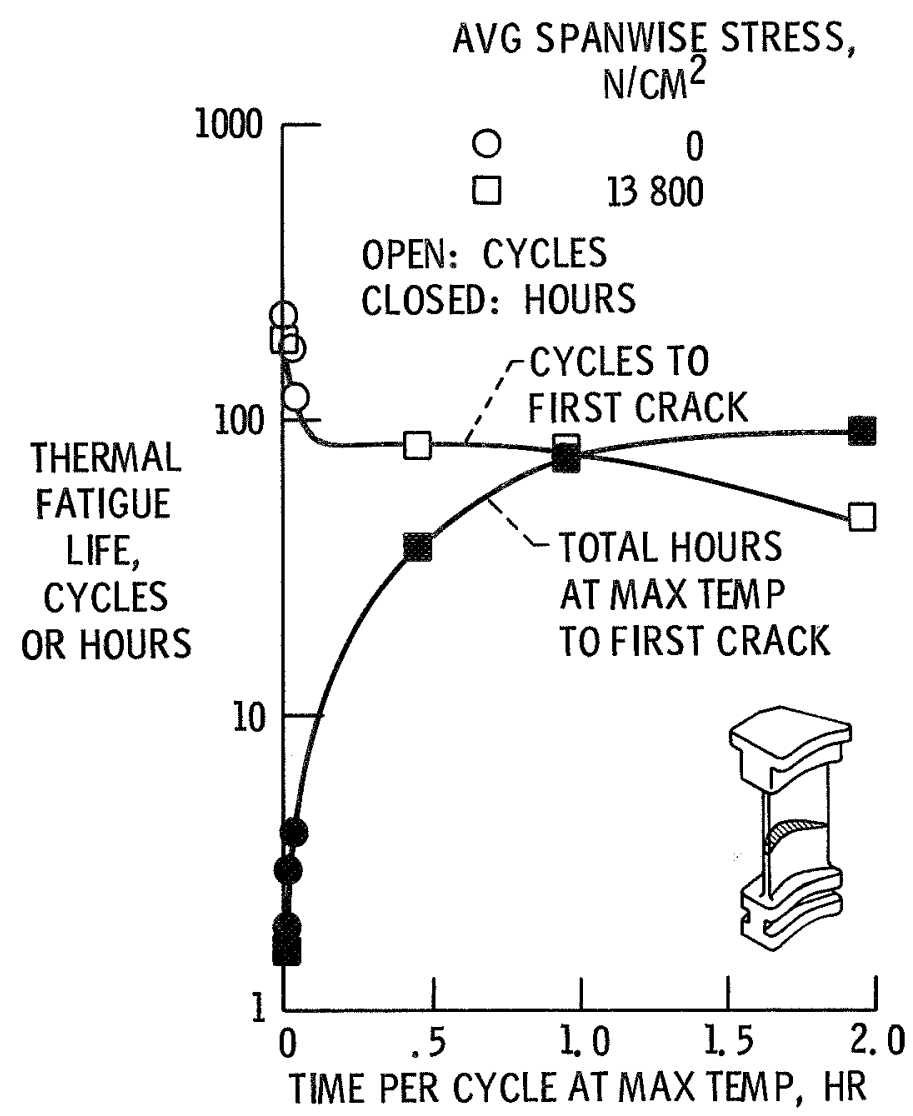

Figure 8. - Effect of hold time on thermal-fatigue life of coated B 1900 simulated turbine blades $(350 \mathrm{~K} \rightleftarrows 1340 \mathrm{~K})$.

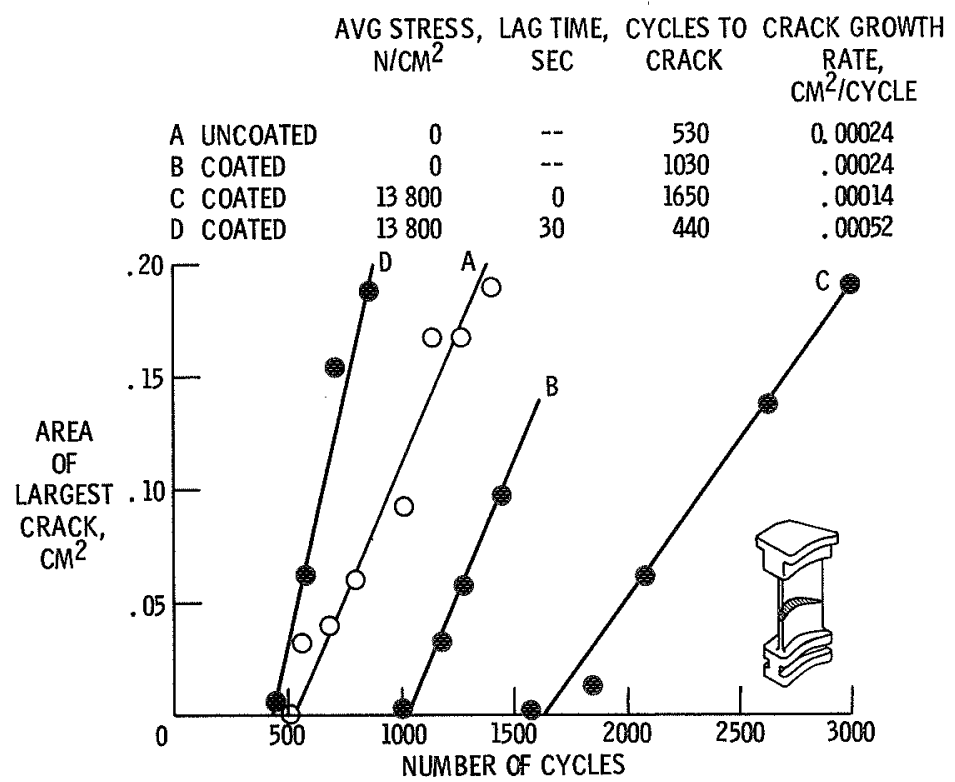

Figure 9. - Thermal-fatigue crack propagation in IN 100 simulated turbine blades $(350 \mathrm{~K} \rightleftarrows 1225 \mathrm{~K})$.

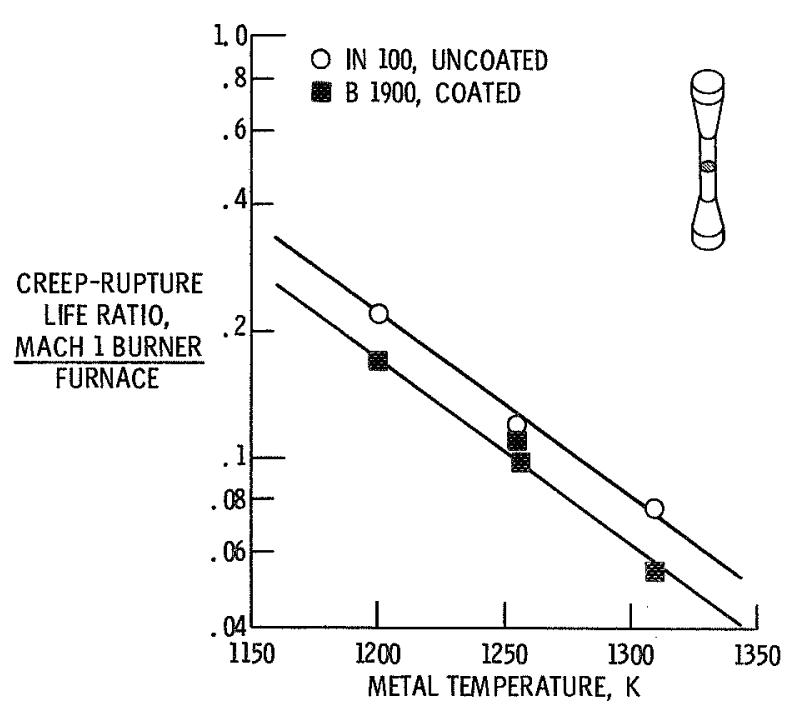

Figure 10. - Effect of gas velocity on creeprupture life of IN 100 and coated B 1900. 